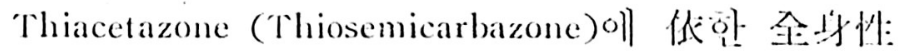

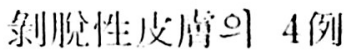

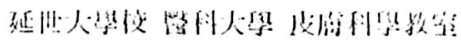 \\ 鞠泓一・哭柱盆・金永來・禹潦河
}

\section{Abstract - \\ Generalized Exfoliative Dermatitis due to Thiacetazone: A Report of Four Cases}

\author{
Hong Il Kook, M.D., Joo Ik Oh, M.D. \\ Yong Rae Kim, M.D. and Tae Ha Woo, M.D.
}

Department of Dermatology, College of Medicine, Yonsei University

\begin{abstract}
Four cases of generalized Exfoliative Dermatitis due to Thiacetazose were reported. All of the cases took this drug for the treatment of pulmonary tulerculosis.

Systemic manitestations such as hadache, nansea, Vomiting, drug fever, and weight loss preceded the skin eruptions and then generalized exfoliations vere developed about 3 weelis later.

Tiwo patients of all showed transicnt poteinuria but all patients had almost normal C. B.C. findings and liver function tests. All patients were abite to treat readily within a few weeles but the careful consideration slould be given for the proper ase of thateclazente.
\end{abstract}

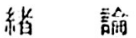

Thiacetazone (Thiosemicarbasone)은 Domagk" अ이

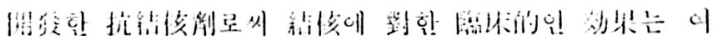

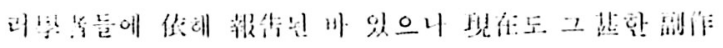

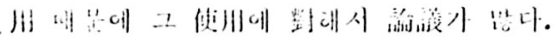

Hinshaw, Mc Dermott

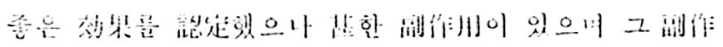

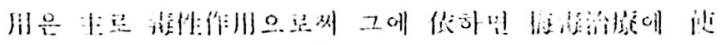

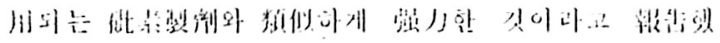
다. Thatetazone은 Iso-niazide 와 의 fith

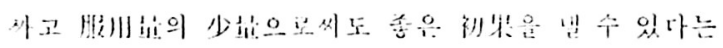

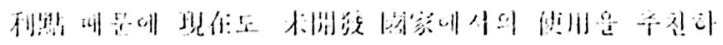

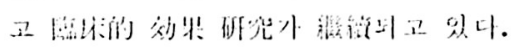

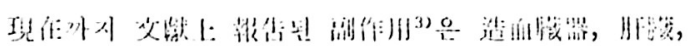

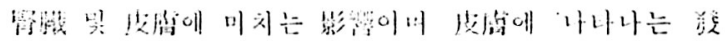

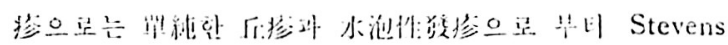

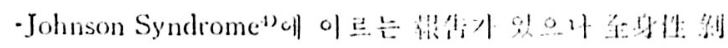

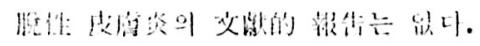

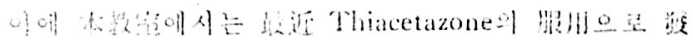

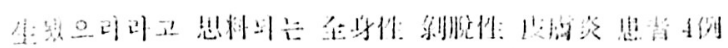

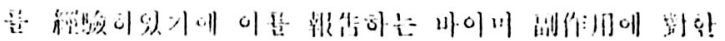

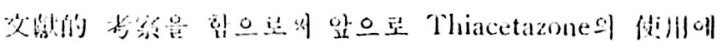

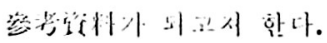

\section{[症例]}

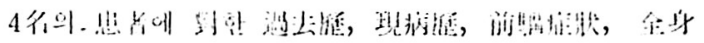

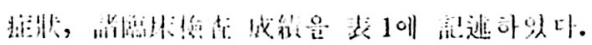

服用理由吴動栈：

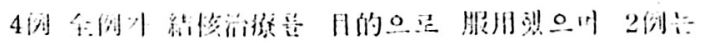

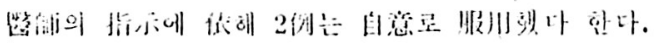

他的와의 併用:

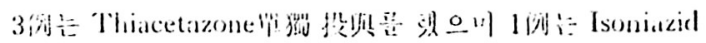

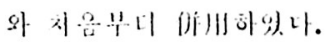

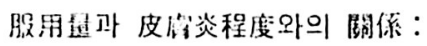

$2($ ii

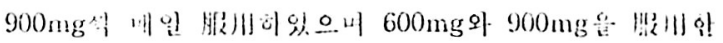

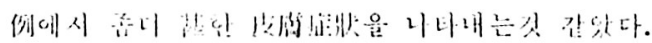

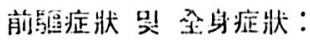

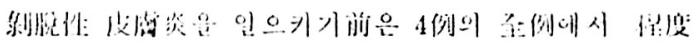

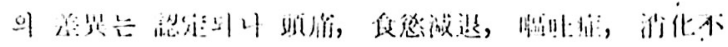

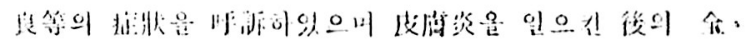


전신성 박탈성·피부염 4 예

\begin{tabular}{|c|c|c|c|c|}
\hline 환자싱명 & 박 00 & 원 00 & $\div 00$ & 박 $\bigcirc \bigcirc$ \\
\hline 령 & 33 & 27 & 46 & 58 \\
\hline ㅂ복 & 여 & 여 & 남 & 남 \\
\hline 내네 원 일 자 & 68.4 .18 & 68.5 .11 & 5.20 & 8.22 \\
\hline 복 용 이 유 & 결 핵 페 & 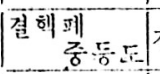 & 견 핵페 겅증 & 견 헥 페 경 증 \\
\hline 붕 용 공 기 & 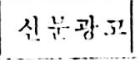 & 의사핯천 & 라·디 오 깅 고 & 보긴소투약 \\
\hline 티야갂사 사잉 & 인 음 & 잆 음 & 잆 은 & I N:H. \\
\hline 하 루복용망 & $300 \mathrm{mg}$ & $900 \mathrm{mg}$ & $300 \mathrm{mg}$ & $600 \mathrm{mg}$ \\
\hline 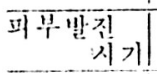 & 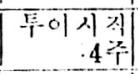 & 2 주 & 6 주 & 3 주 \\
\hline 진구증상 & & & & \\
\hline 1) 둔 통 & $(+)$ & $(t+)$ & $(t)$ & $(t+)$ \\
\hline 2)식역갑 네 & $(t-)$ & $(+)$ & $(+)$ & $(+)$ \\
\hline 3)가 토 증 & $(+)$ & $(+t)$ & $(+)$ & $(++)$ \\
\hline 4) $\because \quad E$ & $(+)$ & $(+)$ & $(-)$ & $(+)$ \\
\hline 5)날 열 & $(+)$ & $(t)$ & $(-)$ & $(+)$ \\
\hline $\begin{array}{l}\text { 6) 국강ㅈㅓㅓ 맙. } \\
\text { 의 케 양: }\end{array}$ & $(+t)$ & $(t+)$ & $(-)$ & $(++)$ \\
\hline 7)소하장에 & $(+)$ & $(+)$ & $(+-)$ & $(+)$ \\
\hline 피부증상 & $\begin{array}{l}\text { 소 양 증 } \\
\text { 진 신 박 탈 }\end{array}$ & $\begin{array}{l}\text { 탈 모 증 } \\
\text { 전신박틸 }\end{array}$ & 전신 박틸. & $\begin{array}{l}\text { Pellagra } \\
\text { jaundice } \\
\text { 자 반 증 } \\
\text { 전 신박탈 }\end{array}$ \\
\hline 전 신중상 & 메 우서 의 & 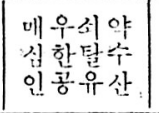 & 시 & $\begin{array}{l}\text { 영양실조 } \\
\text { 탈 수 }\end{array}$ \\
\hline 임 싱김 사 & & & & \\
\hline 1) ำำ 엠 & $\begin{array}{c}\text { III 헝 }-7 \\
4,500 \\
\text { Hb }=12.6 \\
\text { Diff; } \\
\text { Count } \\
\text { Normal }\end{array}$ & 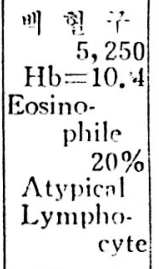 & $\begin{array}{l}\text { W. B C } \\
9,000 \\
\text { Hb=14. } \\
\text { Diff; } \\
\text { Normal } \\
\end{array}$ & $\begin{array}{l}\text { W.B.C. } \\
8,450 \\
\text { Hb }=10.1 \\
\text { Promy- } \\
\text { elocyte } \\
\text { Aniso- } \\
\text { cytosis } \\
\text { Diff: } \\
\text { Normal }\end{array}$ \\
\hline $\begin{array}{l}\text { 2) } \Lambda \text { it } \\
\text { Alumin }\end{array}$ & $\underset{(t)}{\text { Albumin }}$ & $\begin{array}{c}\text { Allowmin } \\
(-1)\end{array}$ & $\begin{array}{r}\text { Albumin } \\
(-)\end{array}$ & $\begin{array}{c}\text { Albumin } \\
(+)\end{array}$ \\
\hline 3)간 기 능 & 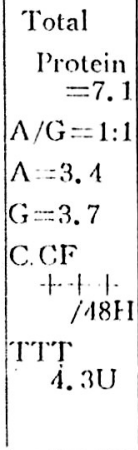 & $\begin{array}{l}\text { Total } \\
\text { Protein } \\
\quad=6.4 \\
\text { A/G }=1: 1 \\
A=3.1 \\
B=3.3 \\
\text { C.CF } \\
+-1.24 \mathrm{H} \\
\text { T'TT } \\
5.6 \mathrm{U}\end{array}$ & 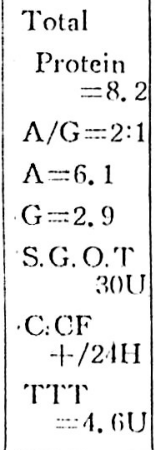 & Not \\
\hline
\end{tabular}

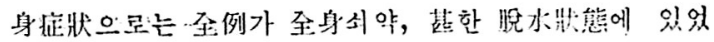

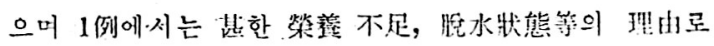
姃㖘㠹絕울 헸었다.

\section{初診時의 ·皮症症狀：}

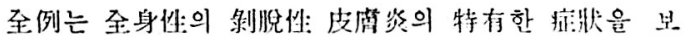

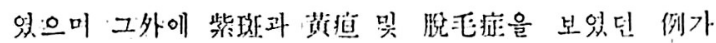
2例 있었다.

\section{諸臨床梌查 成緹:}

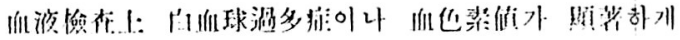

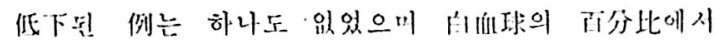
Eosinophilia가 1例 Promyelocyte와 Anisocytosis른 보인

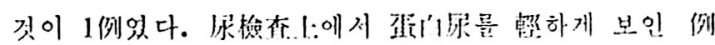

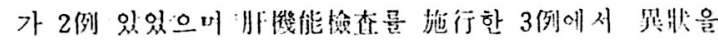
볼 수 없었다.

\section{治療 哭 經過 :}

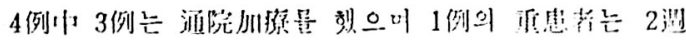

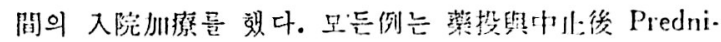

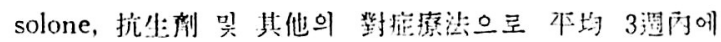
治摚뎄다.

\section{[考察]}

Thiacetazone (Conteban, TB, Berculon A, Amithi-

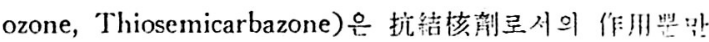

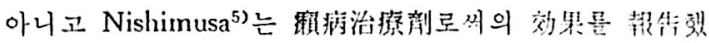

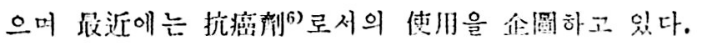

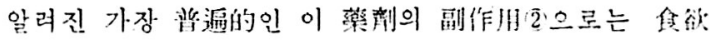

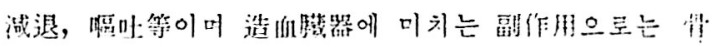

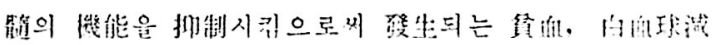

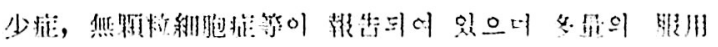

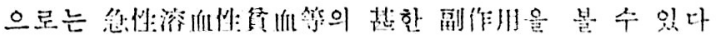

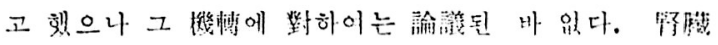

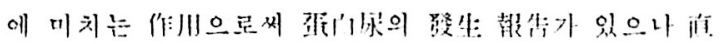

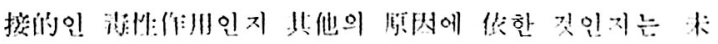

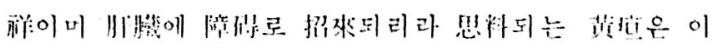

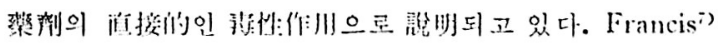

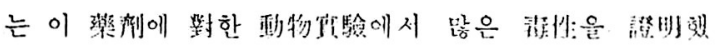

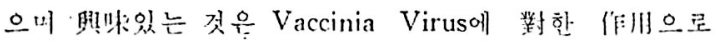

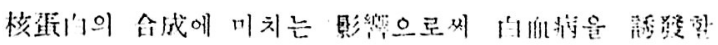

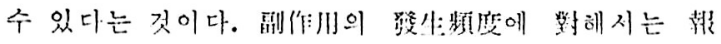

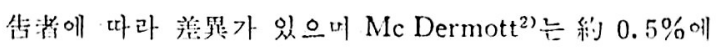

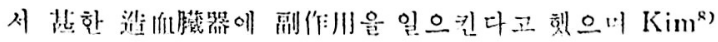

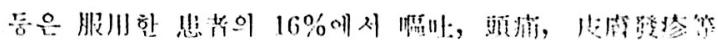

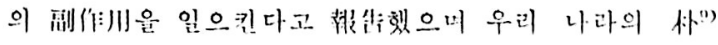

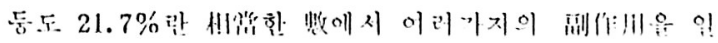

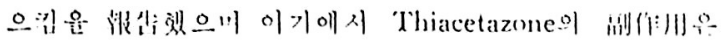




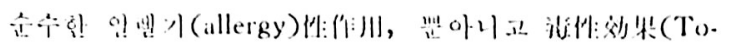

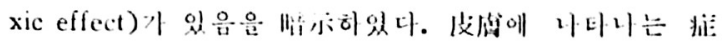

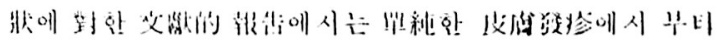
Stevens Johnson Syndromeㄹㅇㅔ 이르는 깃이 있으나 소

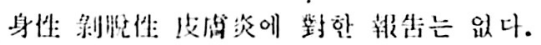

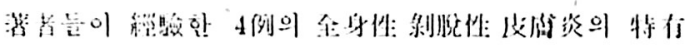

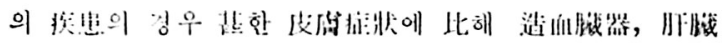

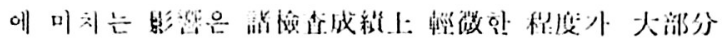

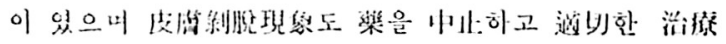

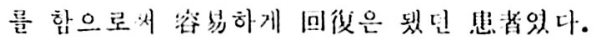

\section{[結論]}

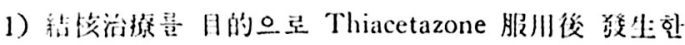

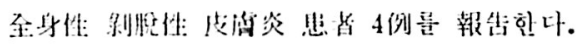

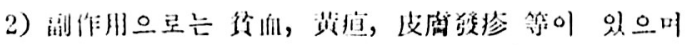

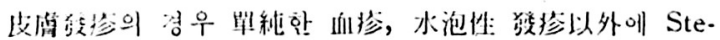
vens. Johinson Syndrome 등이 있다.

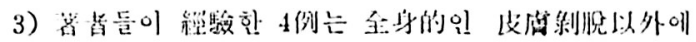

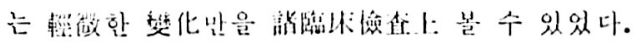

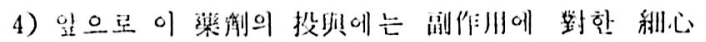

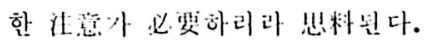

\section{References:}

1) Domagk, G.: Investigation on the antituberculous activity of the thiosemicarbazones in Vitro and in Vivo. Amer. Rev. Tuberc. 61: 8-19 1950

2) Hinshaw, H.C. and McDermott, W.: Thiosemicarbazone therapy of Tuberculosis in Human. Amer.

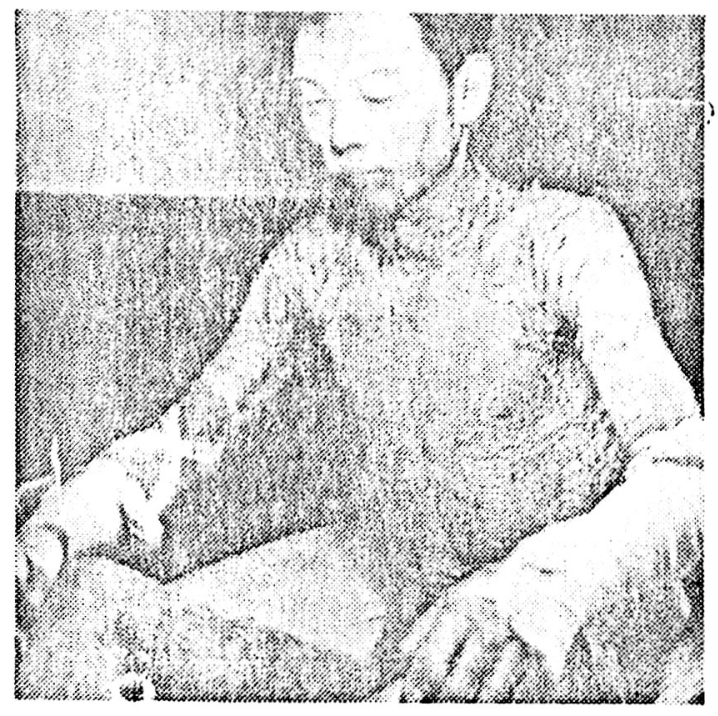

증 례 3 .
Rev. Tuberc. 61:1+5.157 1950

3) Hathaway, W.E.: Possible cause of bone marrow aplasia. New Eng. J. Ned. 27 6:1328.1967

4) Ingle VN, and Banoo (2.: Stevens-Johnson disease associated with administration of a combination of isonicotinic acid hydrazide and thiacetazone.

Indian Pediat. 2: 305.307 1965

5) Nishimura, M., Ogawa, J., Kanetsuna, F., Toda, E., and M. Furuta: Comparative electron micros. cope study of the therapeutic effects Sulfone and Ciba 1906 on lepromatous lesions. Int. J. Lepr. 31:555. 1963

6) Francis, J., Spinks, A. and Stewart. G.T:. The toxic and antituberculous effects of two thiosemicarbazones and streptomycin in dog, monkeys and guinea pigs. Brit. J. Pharmacol. 5: $5+9.5$ $6+1950$

7) Prescott B. and $\mathrm{Li} \mathrm{CP}$ : Long chain thiosemicar. bazone as anticancer and antiviral agents. $J$ Med. Chem. 7.383.+ 1964

8) NG Yook Kim and S. Devi: Thiacetazone/INAH and PAS/INH in the treatment of TB. Far East Med. J. 2 : 189. 1966

9) Sung Uee Park and Hyo Keun Lee: Thiacetazone trial for its toxicity and acceptability by patients on Domiciliary basis in Korea. Korean J. TB. and Respiratory dis. 26:41-4+1967

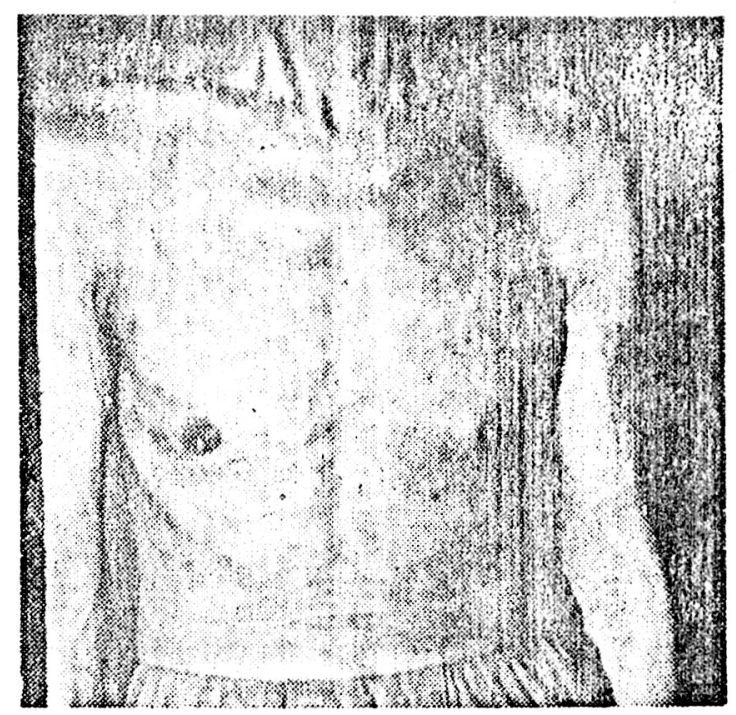

중 래 4 . 